\title{
The Prenatal and Perinatal Risk Variables of the Sensory Processing Disorder
}

\author{
Magdalena Szczepara-Fabian ${ }^{1 *}$, Ewa Emich-Widera ${ }^{2}$, Beata Kazek ${ }^{3}$, Aleksandra Kaniewska ${ }^{1}$ and Justyna Paprocka ${ }^{2}$ \\ ${ }^{1}$ Department of Physiotherapy, Center of Early InterventionPSONI, Żory, Poland \\ ${ }^{2}$ Department of Neuropediatrics, School of Medicine in Katowice Medical University of Silesia, Katowice, Poland \\ ${ }^{3}$ Department of Child Neurology, Child Development Support Center "Persevere" in Katowice, Katowice, Poland \\ *Corresponding author: Szczepara-Fabian M, Department of Physiotherapy, Center of Early Intervention, Żory, Poland, E-mail: magda.lena@op.pl
}

Received date: February 01, 2018; Accepted date: February 16, 2018; Published date: February 23, 2018

Copyright: (02018 Szczepara-Fabian M, et al. This is an open-access article distributed under the terms of the Creative Commons Attribution License, which permits unrestricted use, distribution, and reproduction in any medium, provided the original author and source are credited.

\begin{abstract}
Sensory Processing Disorder has a negative effect on a child's functioning. The etiology and pathomechanics of sensory processing disorder has not yet been fully identified. The prenatal and perinatal variables have been described as the significant causes. The purpose of this work was to determine the most common and presently occurring prenatal and perinatal problems that may serve as the predictors of SPD. The studied group consisted of 89 children with identified sensory processing disorder and no other neurological disorders. The control group consisted of 88 children within the same age group which were healthy and did not suffer from the sensory processing disorder. The retrospective data from the prenatal and perinatal periods were collected through a questionnaire, prepared specifically for the purpose of this project.
\end{abstract}

Besides that, the complex assessment of the children consisted of a pediatrics neurologic and physiotherapy/SI diagnosis examination. The age appropriate checklist, prepared by the American Occupational Therapy Association, has also been used. In the case of children between the ages of 7 months to 3 years old, Georgia A. De Gangi's Infant-Toddler Symptom Checklist was applied. Furthermore, during the examination, the therapist applied the Clinical Observation Checklist as well as the South Carolina Sensory Integration Tests trials for the children above 4 years old. It has been demonstrated that there is a predilection towards the type of sex in sensory processing disorder, and it occurs three times more frequently among boys than among girls, in the studied group. Among all analyzed variables, six of them occurred statistically significantly more frequently in the group with the sensory processing disorder. Considering the frequency of occurrence, those variables included the following: a low birthweight, a low Apgar score at $1 \mathrm{~min}$, infections and cervical insufficiency, and, less frequently occurring, placental abruption. The multivariable analysis demonstrates that the concurrence of two out of six risk variables with the highest prediction results in $80 \%$ probability of the emergence of sensory processing disorder, and the concurrence of 3 variables results in $90 \%$ of that probability. Our research study results indicate that the children with the prenatal and perinatal history should be under a specialized multidisciplinary supervision at least until they start school. In case of the concurrence of two and more variables, such supervision should be mandatory.

Keywords: Sensory processing disorder; Risk variables of sensory processing disorder; Prenatal and perinatal variables

\section{Introduction}

"Sensory Processing Disorder is the difficulty in receiving, organizing and using sensory information, as a result of which the everyday interactions of the particular person with the environment are ineffective [1]". The contemporary name for the sensory integration dysfunction within the central nervous system is Sensory Processing Disorder (SPD). The previously functioning name of sensory integration (SI) has been applied to describe the improvement therapy [2].

Sensory processing disorder includes a broad spectrum of problems with habituation, proper intensity of the unconscious reactions to the known and unknown stimuli from the environment and a general pattern of the dynamics of everyday behaviours. When exposed to regular stimuli, a child may display abnormal behaviours, may avoid certain things, and may not manage well those things others do automatically and without any effort. Children with SPD are easily spotted within the same age group while performing tasks awkwardly, improperly, with delays or not performing them at all, isolating from the group or being obtrusive and ubiquitous. The unusual behaviour is stressful for the child, its family and the environment, and it may be a risk factor for other behavioural disorders [3]. A child who is perceived as awkward, always aggravated, hyperactive, scatter-brained, or altogether hypoactive has often a surprising IR/II result indicating a significant intellectual potential.

Based on the research studies, performed in the USA in 2004, it was demonstrated that sensory processing disorder affects approximately $5 \%$ of children [4]. According to Kranowitz, presently, the problem affects between 10 to $15 \%$ of children [5]. The researchers from Yale University published their research study results which indicated that the parents of $16.5 \%$ of 8 year old children had reported a significant number of the sensory impressions that were disturbing to the children. Those same children demonstrated a three times higher level of stress, aggression and problems with social behaviour, such as interactions with children of the same age, than the children without any reported sensory problems [6]. 
The publications regarding the frequency of the occurrence of SPD that were based on an immediate (face to face) assessment of the studied children are deficient in quantity. There is no formulated pattern that would determine the proper method to collect data. Most of the publications indicate the occurrence of the symptoms of SPD in children based on the answers to the questions, contained in a detailed questionnaire, provided by the parents $[7,8]$.

The published research study results refer to the diagnosis of the full spectrum of SPD as well as the particular areas of the disorder. Van Hulle et al. considered the occurrence of at least 4 symptoms of tactile (touch) or auditory hyper-reactivity to indicate an excessive sensory activity. They found it in $13.5 \%$ of preschool children and $16.5 \%$ of school-age children [9]. Similar results were achieved by Ahn [10] who diagnosed hyper-reactivity in $13.7 \%$ of children starting school.

We can minimize the problems that affect functioning through an adequate sensory organization of the environment and the support of the habituation processes. The earlier the support is initiated, in justified cases, the better the prognosis will be; especially in regards to the social integration. It is worth noticing that we have a lot to offer since the early application of therapy has been proven to be effective [11].

The etiology and pathomechanics of sensory processing disorder, as well as other neurodevelopmental disorders, such as ADHD, has not yet been fully identified. The problems occurring within the prenatal and the perinatal periods have long been considered to be and described as the significant causes of the disorder $[2,12]$.

\section{Methods and Materials}

Sensory Processing Disorder has a negative effect on a child's functioning. It may cause delays in the motor development, as well as it may affect a normal socio-emotional development. The knowledge concerning the sensory processing disorder and its causes is insufficient not only among the society, but also among the doctors of medicine, including in particular, paediatricians, paramedic professionals and educators to whom parents most often report their first alarming concerns regarding the psychomotor development of their child. Identifying significant risk variables may prompt the creation of a special monitoring group for such children.

The purpose of this work was to determine the most common and presently occurring prenatal and perinatal problems that may serve as the predictors of SPD.

\section{Participants}

Sensory processing disorder-SPD group: The studied group (SPD) consisted of 89 children with identified sensory processing disorder and no other neurological disorders, particularly such as epilepsy, spastic diplegia, encephalopathy, myelomeningocele, congenital brain malformations, genetic disorders, mental retardation. The study included 7 month to 18 year old children.

Without SPD-wSPD: 88 children within the same age group, which were healthy and did not suffer from SPD, with the same exclusion criteria applied as with the studied group, were recruited for the control group (without SPD-wSPD).

The information regarding pregnancy and childbirth was collected using medical documentation and a questionnaire filled out by parents with the help of a therapist, which was construed for the purposes of this project (Annex $\mathrm{nr}$ 1). It included information regarding pregnancy, childbirth, and the sensorimotor development. During the prenatal period, it referred to: the mother's chronic illnesses, multiple pregnancy, bleeding, infections, drugs, serological incompatibility, oligohydramnios/polyhydramnios, cervical insufficiency, bed rest, placental abruption, C-section, preterm birth, (at $37^{\text {th }}$ week or earlier), instrumental delivery, abnormal birth-weight to the gestational age (too low or too high, as according to the Fenton's growth charts), Apgar score, fetal abnormalities, prolonged jaundice.

Besides the complex child's assessment interview, a paediatric neurologic and physiotherapy/SI diagnosis examination, along with the use of the age appropriate checklist, prepared by the American Occupational Therapy Association, has also been performed.

In the case of the children between the ages of 7 months to 3 years old, Georgia A. De Gangi's Infant-Toddler Symptom Checklist was applied. Furthermore, during the examination, the therapist applied the Clinical Observation Checklist as well as the South Carolina Sensory Integration Tests trials for the children above 4 years old. For the final assessment, the observation of a non-directive and directive play, besides the analysis of the data collected with the help of the abovementioned tools, turned out to be significantly meaningful.

\section{Results}

It has been demonstrated that there is a predilection towards the type of sex in the studied group, and it occurs three times more frequently among boys than among girls (75.28\% vs. 24.72\%) (Table 1).

\begin{tabular}{|l|l|l|l|}
\hline Sex & $\begin{array}{l}\text { SPD } \\
\mathbf{n = 8 9}(\mathbf{1 0 0 \% )}\end{array}$ & $\begin{array}{l}\text { Control } \\
\mathbf{n = 8 5} \\
\mathbf{( 1 0 0 \% )}\end{array}$ & Fisher Exact Probability Test \\
\hline Female & $22(24.72 \%)$ & $\begin{array}{l}34 \\
(40.00 \% \\
)\end{array}$ & \\
\hline Male & $67(75.28 \%)$ & $\begin{array}{l}51 \\
(60.00 \%\end{array}$ & \\
& & $p=0.04$ \\
\hline
\end{tabular}

Table 1: Distribution of sex within the SPD group and the control group.

In Table 2, the analyzed risk variables have been presented; placenta previa, instrumental delivery and fetal abnormalities were excluded from the statistical analysis as they were found only in individual instances.

Six out of all of the analyzed risk variables occurred significantly statistically more frequently within the SPD group than within the wSPD group. Considering the frequency of their occurrence, those variables included the following: abnormal birth-weight (25\%), low Apgar score at $1 \mathrm{~min}(22.35 \%)$, cervical infections and insufficiency (18.6\% in both cases), less frequently placental abruption (10.47\%).

The Apgar score at 1 min seems to be significant here. 19 children from the SPD group $(22.35 \%)$ and only 2 children from the wSPD group (2.47\%) were assessed to have an Apgar score of less than 7 but greater than 3. Out of all recruited children, in both groups, none of them had an Apgar score of less than 3. 
Citation: Szczepara-Fabian M, Emich-Widera E, Kazek B, Kaniewska A, Paprocka J (2018) The Prenatal and Perinatal Risk Variables of the Sensory Processing Disorder. Clinics Mother Child Health 15: 286. doi:10.4172/2090-7214.1000286

Page 3 of 5

\begin{tabular}{|c|c|c|c|}
\hline Risk variable & $\begin{array}{l}\text { SPD } \\
\mathrm{m} / \mathrm{n}(\%)\end{array}$ & $\begin{array}{l}\text { wSPD } \\
\mathrm{m} / \mathrm{n}(\%)\end{array}$ & Fisher Exact Probability Test \\
\hline Mother's chronic illnesses & 6/61 (9.84\%) & 7/81 (8.64\%) & NS $(p=0.99)$ \\
\hline Bleeding & $19 / 81(23.46 \%)$ & $10 / 85(11.76 \%)$ & NS $(p=0.07)$ \\
\hline Infections & $15 / 80(18.75 \%)$ & $3 / 85(3.53 \%)$ & $p=0.002$ \\
\hline Addictions & $5 / 89(5.62 \%)$ & $1 / 85(1.18 \%)$ & NS $(p=0.21)$ \\
\hline Bed rest & $17 / 84(20.24 \%)$ & 9/85 (10.59\%) & NS $(p=0.09)$ \\
\hline Fetal abnormalities & $1 / 89(1.12 \%)$ & $2 / 85(2.35 \%)$ & NS $(p=0.61)$ \\
\hline Oligohydramnios/polyhydramnios & $1 / 87(1.15 \%)$ & $0 / 85(0 \%)$ & NS $(p=0.99)$ \\
\hline Serological incompatibility & $0 / 86(0 \%)$ & $1 / 85(1.18 \%)$ & NS $(p=0.50)$ \\
\hline Placenta previa & $5 / 86(5.81 \%)$ & $2 / 85(2.35 \%)$ & NS $(p=0.44)$ \\
\hline Cervical insufficiency & $16 / 86(18.60 \%)$ & $6 / 85(7.06 \%)$ & $p=0.04$ \\
\hline Placental abruption & 9/86 (10.47\%) & $0 / 85(0 \%)$ & $p=0.003$ \\
\hline C-section & $33 / 89(37.08 \%)$ & $33 / 85(38.82 \%)$ & NS $(p=0.88)$ \\
\hline Weeks at birth $<37$ & $10 / 89(11.24 \%)$ & $5 / 82(6.10 \%)$ & $N S(p=0.29)$ \\
\hline Apgar $(1 \mathrm{~min})<7$ & $19 / 86(22.35 \%)$ & $2 / 81(2.47 \%)$ & $p=0.00009$ \\
\hline Jaundice & $23 / 73(31.51 \%)$ & $18 / 84(21.43 \%)$ & NS $(p=0.20)$ \\
\hline Weight $<2$ SD & $9 / 84(10.71 \%)$ & $2 / 81(2.47 \%)$ & $p=0.05$ \\
\hline Weight >2 SD & $12 / 84(14.29 \%)$ & $2 / 81(2.47 \%)$ & $p=0.01$ \\
\hline Abnormal birth-weight & $21 / 84(25.00 \%)$ & $4 / 81(4.94 \%)$ & $p=0.0004$ \\
\hline
\end{tabular}

Table 2: Occurrence of risk variables in SPD group and wSPD group.

Spotting during pregnancy $(23.46 \%$ vs. $11.76 \%)$, bed rest $(20.24 \%$ vs. $20.24 \%)$ and premature birth (11.24\% vs. $6.10 \%)$ occurred more frequently within the studied group than within the control group, but without any statistical significance. Neither of the group consisted of children born extremely early. Two children from the SPD group were born between $28^{\text {th }}$ and $31^{\text {st }}$ week. None of the children from the wSPD group were born before the $35^{\text {th }}$ week. C-sections and the mother's chronic illnesses occurred with similar frequency in both groups.

There were 23 children (25.84\%) in SPD group and 34 children $(40.00 \%)$ in wSPD group without any of the considered variables. Table 3 shows the distribution of the number of the concurring risk variables among the full list of considered variables (listed in table 1 for the SPD group and wSPD group).

The difference in the distribution of the results in both groups is statistically significant at the significance level of $p=0.02$ (Chi-square Test of Association with Yates continuity correction).

Starting with the concurrence of 3 risk variables, a higher percentage of such children was found within the SPD group, comparing to the controlled wSPD group. Based on the results included in Table 3, the frequency of the occurrence of SPD was determined among the children with different numbers of the concurring risk variables (Figure 1).

\begin{tabular}{|l|l|l|}
\hline $\begin{array}{l}\text { Number of concurring } \\
\text { risk variables }\end{array}$ & $\begin{array}{l}\text { Control } \mathbf{n = 8 5} \\
(\mathbf{1 0 0 \% )}\end{array}$ & $\begin{array}{l}\text { Chi-square Test of } \\
\text { Association with Yates } \\
\text { continuity correction }\end{array}$ \\
\cline { 1 - 2 } 0 & $34(40.00 \%)$ & \multirow{2}{*}{$\mathrm{N}=0.02$} \\
\cline { 1 - 2 } & $31(36.47 \%)$ & \\
\cline { 1 - 2 } & $10(11.76 \%)$ & \\
\cline { 1 - 2 } & $6(7.06 \%)$ & \\
\cline { 1 - 2 } & $3(3.53 \%)$ & \\
\cline { 1 - 2 } 5 & $1(1.18 \%)$ & \\
\cline { 1 - 2 } & &
\end{tabular}

Table 3: The number of children in the groups with the number $n$ of the diagnosed risk variables (full list of the studied risk variables).

If 3 and more prenatal and perinatal risk variables occur simultaneously, the frequency of the occurrence of SPD is greater than $50 \%$, and the emergence of SPD is then probable. 
The assessment of the concurrence of those risk variables that were identified earlier to be occurring significantly statistically more frequently within the SPD group than within the wSPD group, such as spotting, infections, cervical insufficiency, placental abruption, Apgar score (at $1 \mathrm{~min}$ ) of $<7$, abnormal birth-weight (too low or too high), also seemed to be meaningful.

\begin{tabular}{|c|c|c|c|}
\hline $\begin{array}{l}\text { Number of concurring } \\
\text { risk variables }\end{array}$ & $\begin{array}{l}\text { SPD } \\
n=89 \\
(100 \%)\end{array}$ & $\begin{array}{l}\text { wSPD } \\
n=85 \\
(100 \%)\end{array}$ & $\begin{array}{l}\text { Chi-square Test of } \\
\text { Association with Yates } \\
\text { continuity correction }\end{array}$ \\
\hline 0 & $\begin{array}{l}40 \\
(44.96 \%)\end{array}$ & $\begin{array}{l}63 \\
(74.12 \%)\end{array}$ & \multirow{4}{*}{$p=0.0002$} \\
\hline 1 & $\begin{array}{l}22 \\
(24.72 \%)\end{array}$ & $\begin{array}{l}16 \\
(18.82 \%)\end{array}$ & \\
\hline 2 & $\begin{array}{l}19 \\
(21.35 \%)\end{array}$ & $6(7.06 \%)$ & \\
\hline 3 and more & $8(8.99 \%)$ & $0 \%$ & \\
\hline
\end{tabular}

Table 4: The number of children in groups with the diagnosed number of concurring risk variables (for 6 identified, statistically significant variables).

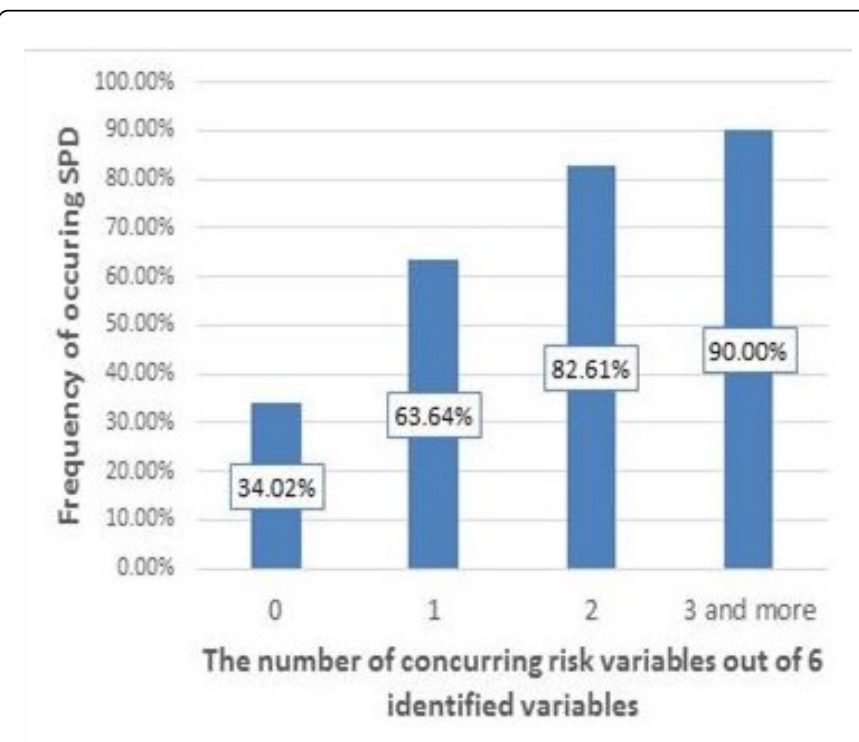

Figure 1: The number of children in groups depending of the number of the concurring, statistically significant risk variables C-P.

The difference in the distribution, shown in Table 4, is statistically significant at the significance level of $\mathrm{p}=0.000003$ (Chi-square Test of Association with Yates continuity correction). There were 40 children $(44.96 \%)$ in SPD group and 63 children $(74.12 \%)$ in wSPD group without any of the six analyzed variables. If 2 of the analyzed variables occurred simultaneously, the greater percentage of the children displaying them was within the SPD group than within the wSPD group. Based on the results shown in Table 4, the frequency of the occurrence of SPD among the children with different numbers of the concurring risk variables was determined. The concurrence of at least 3 risk variables from the list, including spotting/bleeding, infections, cervical insufficiency, placental abruption, Apgar score (at $1 \mathrm{~min}$ ) of $<7$, abnormal birth-weight, was found only in 1 child with SPD.

The multivariable analysis demonstrates that the concurrence of 2 risk variables from the list of 6 variables with the highest prediction results in $80 \%$ probability of the emergence of SPD; for 3 variables, it is $90 \%$ probability.

\section{Discussions}

The current knowledge regarding the causes, the mechanism and the evolution of the symptoms in the individual's life regarding the scope of the sensory processing is limited. Different risk variables predisposing to the emergence of that disorder, including the prenatal and perinatal problems, have been described. C-section used to be considered to be a factor here as this delivery method does not activate this specific training of assimilating the somatosensory stimuli $[13,14]$. This subject is rather omitted in the latest reports, though. Nevertheless, we have to admit that C-section is a dependent variable, as in most cases there are serious causes leading to the decision about performing a C-section delivery. In addition to that, as it is proven in our studies, C-section delivery history concerns the children from the SPD group almost as equally frequently as it does the children from the wSPD group.

Publications also point out to the gestational age, especially the extremely early gestational age. Premature birth (prior to $37^{\text {th }}$ week) causes a child to develop in a non-physiological environment where the exposure to different sensory stimuli forestalls the critical period and collides with the normally developing sensory integration $[11,15]$. Premature children have less possibility to feel the pressure in the womb and the strong resistance to movements of the body (too little proprioception). The vestibular stimulation is also poor especially in the opposite position of a head which a child usually undertakes not earlier than in the ninth month of pregnancy. Among all of the children recruited for our study none of them were born at an extremely early gestational age, which seems to be a significant predictor of SPD.

In total, fifteen children were born prematurely (after the end of $32^{\text {nd }}$ and before the end of $37^{\text {th }}$ week of gestation). It mainly concerned the children from the SPD group (10 SPD vs. 5 wSPD), but it still did not constitute a statistically significant difference.

The next considered SPD related variable is the abnormal birthweight. The results of our pilot studies are consistent with Brazelton's observations who have described the relationship between the intrauterine growth restriction and the increased sensory reactivity [16]. According to Miller, birth-weight that is too low or too high poses as the risk variable [12]. May-Benson has also noted a higher than average birth-weight in children with SPD [17].

The everyday activity of a pregnant woman is important for the developing foetus. A natural and not very intense physical activity is quite significant for the future development of a child, especially for the development of the basic sensory systems (ventricular, tactile, and proprioceptive) [18]. Therefore, bed rest, suggested by the doctor, due to, among others, cervical insufficiency or placenta previa, is not indifferent to the development of the sensory system. It was evidenced, though, that the suggestion of applying the bed rest treatment often concerned the mothers of the children from the controlled group, too. Ultimately, it was evidenced in our study that the bed rest treatment 
Citation: Szczepara-Fabian M, Emich-Widera E, Kazek B, Kaniewska A, Paprocka J (2018) The Prenatal and Perinatal Risk Variables of the Sensory Processing Disorder. Clinics Mother Child Health 15: 286. doi:10.4172/2090-7214.1000286

Page 5 of 5

was applied more frequently with the mothers of the children with SPD, but without the attributes of statistical significance.

A prolonged neonatal jaundice has also drawn the researchers' attention in the earlier publications [17] as bilirubin may accumulate in the basal ganglia, in the area of which the processes of the development of sensory integration take place. The clinical observation prove that those children often show abnormal regulation mechanisms within the first weeks of life (tendency for colic, inconsolable crying or whining in infants or difficulties with regulating sleeping and eating; or the opposite of it-apathy, sleepiness, difficulties with perception), which has also been pointed out by Miller [2]. The results of our analysis do not confirm, though, that the prolonged jaundice is the predictor of SPD. Perhaps, lack of any significant difference between the SPD and wSPD groups is related to the continually improving prenatal and perinatal care that results in the fact that jaundice is not as strong, and it lasts for a shorter amount of time.

\section{Conclusion}

The results of our research study indicate that the children with the prenatal and perinatal history, especially such as spotting/bleeding, intrauterine infections, cervical insufficiency, placenta abruption, Apgar score at $1 \mathrm{~min}$ of $<7$, abnormal birth-weight, should be under a specialized multidisciplinary supervision at least until they start school. In case of the concurrence of two and more of the abovementioned variables, such supervision should be mandatory. It is worth paying a special attention to due to the significant relationship between the sensory processing disorder and the school problems, as many researchers have already demonstrated previously.

\section{Acknowledgement}

The research was approved by Bioethical Commission of Medical University of Silesia, Katowice, Poland.

This work has been supported by Institutional grant of Medical University of Silesia KNW-1- 126/K/6/K/.

\section{References}

1. Kranowitz CS (2012) Nie-zgrane dziecko. Zaburzenia przetwarzania sensorycznego-diagnoza i postepowanie, Harmonia Universalis, Gdańsk.

2. Miller LJ (2016) Dzieci w świecie doznań. Jak pomóc dzieciom Z zaburzeniami przetwarzania sensorycznego?, Harmonia Universalis, Gdańsk.
3. Ben-Sasson A, Carter AS, Briggs-Gowan MJ (2010) The development of sensory over-responsivity from to elementary school. J Abnorm Child Psychol 38: 1193- 2002.

4. Ahn RR, Miller LJ, Milberger S, McIntosh DN (2004) Prevalence of parents' perceptions of sensory processing disorders among kindergarten children. Am J Occup Ther 58: 287-293.

5. Kołat N (2014) Zaburzenia przetwarzania sensorycznego u dziecidiagnostyka i postępowanie. Nowa Pediatria 3: 97-102.

6. Ben-Sasson A, Carter AS, Briggs-Gowan MJ (2009) Sensory overresponsivity in elementary school: prevalence and social-emotional correlates. J Abnorm Child Psychol 37: 705-716.

7. Bar-Shalita T, Vatine JJ, Parush S (2008) Sensory modulation disorder: a risk factor for participation in daily life activities. Dev Med Child Neurol 50: 932-937.

8. Bart O, Shayevits S, Gabis LV, Morag I (2011) Prediction of participation and sensory modulation of the late preterm infants in 12 months, a prospective study. Res Dev Disabil 32: 2732-2738.

9. Hulle C van, Lemery-Chalfant K, Goldsmith H (2015) Trajectories of sensory over-responsivity from early to middle childhood: birth and temperament risk factors. PLoS One 10: e0129968.

10. Ahn RR, MillerLJ, Milberger S, McIntosh DN (2004) Prevalence of parents' perceptions of sensory processing disorders among kindergarten children. Am J Occup Ther 58: 287-293.

11. Ryckman J, Hilton C, Rogers C, Pineda R, (2017) Sensory processing disorder in preterm infants during early childhood and relationships to early neurobehavior. Early Human Developmen 113: 18-22.

12. Miller LJ (2003) Outcome of sensory based intervention after birth trauma: final report for NIH. Planning Grant. RFA\#1R21HD/ AR41614-01.

13. Ayres AJ (2015) Dziecko a integracja sensoryczna, Harmonia Universalis, Gdańsk.

14. Wiśniewska M (2012) Diagnostyka zaburzeń procesów integracji sensorycznej u małych dzieci. Pediatria Polska 87: 278-285.

15. Kmita G (2013) Od zaangażowania do zaciekawienia. O rozwoju samoregulacji $\mathrm{w}$ interakcjach $\mathrm{z}$ rodzicami niemowląt urodzonych skrajnie wcześnie, przedwcześnie i o czasie. Wydawnictwo Uniwersytetu Warszawskiego, Warszawa.

16. Brazelton T, Sparrow JD (2013) Rozwój dziecka od 0 do 3lat, Wydawnictwo GWP, Sopot.

17. May-Benson TA, Komar JA, Teasdale A (2009) Incidence of pre-, peri and post-natal birth and children with autism spectrum disorder. Front Integr Neurosci 3: 31.

18. Maas VF (2016) Uczenie się przez zmysły, Harmonia Universalis, Gdańsk. 